\title{
HRP-mediated polyacrylamide graft modification of raw jute fabric
}

\author{
Ruirui Liu ${ }^{\mathrm{a}}$, Aixue Dong ${ }^{\mathrm{a}}$, Xuerong Fan ${ }^{\mathrm{a}, \mathrm{b}}$, Qiang Wang ${ }^{\mathrm{a}, \mathrm{b}, *}$, \\ Yuanyuan $\mathrm{Yu}^{\mathrm{a}}$, Artur Cavaco-Paulo ${ }^{\mathrm{b}, \mathrm{c}}$ \\ ${ }^{a}$ Key Laboratory of Science and Technology of Eco-Textile, Ministry of Education, Jiangnan University, Wuxi, 214122 Jiangsu, China \\ ${ }^{\mathrm{b}}$ International Joint Research Laboratory for Textile and Fiber Bioprocesses, Jiangnan University, Wuxi, 214122 Jiangsu, China \\ ${ }^{\mathrm{c}}$ Department of Biological Engineering, University of Minho, Campus de Gualtar, 4710-057 Braga, Portugal
}

\section{A R T I C L E I N F O}

\section{Article history:}

Received 17 December 2014

Received in revised form 27 February 2015

Accepted 7 March 2015

Available online 14 March 2015

\section{Keywords:}

Horseradish peroxidase

Acrylamide

Hydrophilicity

Graft polymerization

Jute fabric

\begin{abstract}
A B S T R A C T
The horseradish peroxidase (HRP)/hydrogen peroxide system can catalyze the free-radical polymerization of aromatic compounds such as lignins. In this study, to improve the hydrophilicity of lignin-rich jute fabrics, acrylamide (AM) was grafted onto their surface by HRP-mediated oxidative polymerization. The resulting AM-lignin graft polymer in jute fibers, from which the lignin was removed by extracting with dioxane, was characterized by gel permeation chromatography, elemental analysis, matrix-assisted laser desorption/ionization mass spectrometry, nuclear magnetic resonance, scanning electron microscopy, and Fourier transform infrared spectroscopy. The results show that AM was grafted to the jute fiber by HRP. Furthermore, the hydrophilicity of the fabrics was determined in terms of wetting time, balance moisture regain, and static contact angle. Compared to the control sample, the wetting time, balance moisture regain, and static contact angle of the grated fabrics varied from $11.62 \mathrm{~min}$ to $7.45 \mathrm{~min}$, from $9.78 \%$ to $10.40 \%$, and from $122.30^{\circ}$ to $92.84^{\circ}$, respectively, indicating that the hydrophilicity of the raw jute fabric improved. The modification conditions of the HRP-catalyzed AM-grafting reaction were optimized in terms of the nitrogen content of the jute fabrics.
\end{abstract}

(c) 2015 Elsevier B.V. All rights reserved.

\section{Introduction}

As a widely-used household and industrial textile material [1,2], raw jute fiber has some shortcomings such as rigidity, scratchiness, poor hydrophilicity and dyeing property due to the high content of lignin (approximately 16\%), which is a complex threedimensional amorphous polymer consisting of $p$-hydroxyphenyl $(\mathrm{H})$, guaiacyl $(\mathrm{G})$ and syringyl (S) units [3]. These shortages of jute fiber seriously affect the quality of its products, making them merely usable for low-grade goods such as packaging fabrics and bags. Two traditional grafting modifications, i.e., chemical initiation [4] and high-energy irradiation initiation [5,6], could improve the properties of jute fibers, but some deficiencies like the homopolymerization of monomers and severe damage to fibers limit their application. To date, enzymatic grafting modification has been proved to be an important and feasible method as an alternative to traditional approaches because of their eco-friendly nature and mild reaction conditions $[7,8]$.

\footnotetext{
* Corresponding author at: Key Laboratory of Science and Technology of EcoTextile, Ministry of Education, Jiangnan University, Wuxi, 214122 Jiangsu, China. Tel.: +86 510 85912007; fax: +8651085912009.

E-mail address: qiang_wang@163.com (Q. Wang).
}

Horseradish peroxidase (HRP, EC1.11.1.7) is a plant peroxidase obtained from the roots of horseradish. It readily combines with hydrogen peroxide $\left(\mathrm{H}_{2} \mathrm{O}_{2}\right)$ and the resultant $\mathrm{HRP}-\mathrm{H}_{2} \mathrm{O}_{2}$ complex can oxidize a wide variety of hydrogen donors like aromatic compounds [9]. Recently, HRP-catalyzed free-radical polymerization has been used for the synthesis of polymers from varied monomers [10]. Sgalla et al. [11] obtained a novel 4-phenylphenol ortho dimer and revealed the reactivity of HRP with water insoluble phenolic compounds in ionic liquid/water mixtures. Chul and Young [12] studied the free-radical polymerization of aniline initiated by the $\mathrm{HRP}-\mathrm{H}_{2} \mathrm{O}_{2}$ system in a nonaqueous phase and obtained a polyaniline product directly connected to benzene. Moreover, Lv et al. [13] reported the copolymerization of starch and different monomers such as dimethyl diallyl ammonium chloride initiated by HRP. In addition, the HRP-mediated vinyl polymerizations in the presence of $\mathrm{H}_{2} \mathrm{O}_{2}$ and $\beta$-diketone [14] have been also carried out using hydrophilic monomers such as acrylamide (AM) [15] and hydrophobic monomers such as methyl methacrylate [16], styrene derivatives [17,18] and 2-vinylnaphthalene [17]. The homopolymerization of AM [19,20], copolymerization of lignin and phenols [21] and polymerization of lignosulfonates [22] catalyzed by HRP have provided theoretical and experimental foundation for the grafting polymerization of AM onto the surfaces of jute fibers. 


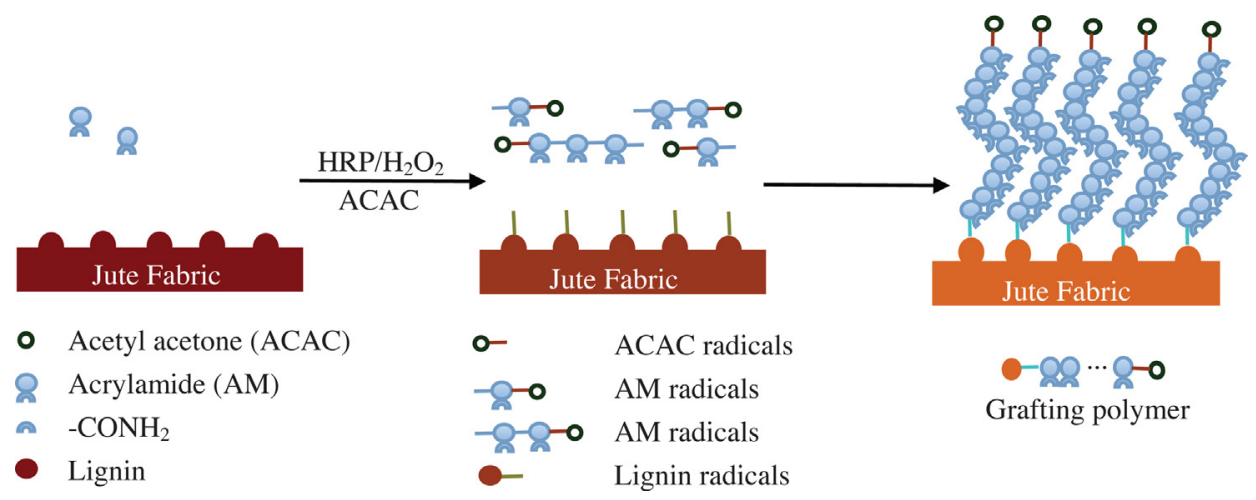

Fig. 1. Schematic illustration of HRP-catalyzed grafting reaction of acrylamide (AM) onto the jute fabric.

In the present work, HRP was used to catalyze the free-radical copolymerization of AM and lignin on the surface of jute fibers, thus grafting AM onto the jute fiber surface and improving the moisture absorption, wettability, etc. of the resulting jute fiber. AM was enzymatically grafted onto the jute fabric surface by HRP, as illustrated in Fig. 1. The proposed pathway of the enzymatic reaction is shown in Fig. 2. As far as our knowledge goes, this is not only the first attempt for the functional modification of jute fabric using HRP, which is efficient, environmentally friendly, and does not damage the material, but also a new application of HRP in textile processing.

\section{Experimental}

\subsection{Materials and reagents}

The $100 \%$ raw jute fabric, with a $7 / 7$ (warp/weft) $\mathrm{cm}^{-1}$ yarn density, was supplied by Longtai Weaving Company (Changshu, China). Plant HRP stored at $-20^{\circ} \mathrm{C}$, and $\mathrm{AM}$ were obtained from Aladdin Reagent Ltd. (Shanghai, China). The HRP was used directly as received without further purification. All the other chemicals used in this study were commercially available and of analytical grade.

\subsection{HRP assay}

First, an HRP solution was prepared by dissolving $25 \mathrm{mg}$ HRP in $25 \mathrm{~mL}$ of distilled water at $4^{\circ} \mathrm{C}$. The enzymatic activity of HRP at $30^{\circ} \mathrm{C}$ was measured spectrophotometrically by monitoring the oxidation of gallic acid, as the substrate, at $420 \mathrm{~nm}$ in $0.1 \mathrm{M}$ phosphate buffer ( $\mathrm{pH} 7.0$ ) with diethyl ether, as the extraction agent. The enzymatic activity was expressed as milligrams of oxidized gallic acid extracted with $100 \mathrm{~mL}$ diethyl ether per minute [23]. The enzymatic activity was $332 \mathrm{U} / \mathrm{mg}$, calculated as follows:

$\operatorname{HRP}(\mathrm{U} / \mathrm{mg})=E_{420} \times 8.5 \times E_{w}$

where $E_{420}$ is the absorbance at the wavelength of $420 \mathrm{~nm}, E_{w}$ is the weight of the enzyme, and 8.5 was derived from the unit definition and principle that the absorbance at the wavelength of $420 \mathrm{~nm}$ is 1.000 when $8.5 \mathrm{mg}$ of oxidized gallic acid is extracted with $100 \mathrm{~mL}$ diethyl ether.

\subsection{Isolation of lignin from jute fibers}

The lignin in jute fibers was extracted using a method described by Evtuguin et al. [24-26].

\subsection{Copolymerization of AM and lignin catalyzed by HRP}

First, $0.2 \mathrm{~g}$ of lignin, $100 \%$ of $\mathrm{AM}$, and $0.1 \mathrm{~mL}$ of acetylacetone (ACAC) were dissolved in $30 \mathrm{~mL}$ phosphate buffer $(0.1 \mathrm{M}, \mathrm{pH} 7.0)$ in a reaction vessel, and the incubation was started by adding $0.2 \mathrm{~mL} \mathrm{H}_{2} \mathrm{O}_{2}$ and $0.1 \mathrm{mg} \mathrm{HRP}$. The reaction was maintained at $30^{\circ} \mathrm{C}$ for $4 \mathrm{~h}$. Then, the lignin was centrifuged with a certain volume of ethanol/water (3:7) (v/v) and collected by freeze-drying [19,20]. The control sample, sample treated with inactivated HRP, and sample treated with either HRP or AM followed the same treatment conditions, as mentioned above.

\subsection{Pretreatment of jute fabrics}

The jute fabric samples were desized by boiling with distilled water for $2 \mathrm{~h}$. The iodine-potassium iodide method was used to examine whether the starch or polyvinyl alcohol (PVA) sizes were dislodged completely or not.

\subsection{HRP-mediated grafting of AM onto jute fiber surfaces}

The jute fabric sample $(1 \mathrm{~g})$ was incubated with $50 \mathrm{~mL}$ of phosphate buffer $(0.1 \mathrm{M}, \mathrm{pH} 7.0)$, containing $100 \%$ of $\mathrm{AM}$, a certain volume of ACAC, and HRP in $250 \mathrm{~mL}$ three-neck round-bottom flask under shaking. Then, $\mathrm{H}_{2} \mathrm{O}_{2}$ (30 wt\%) was added dropwise after the mixture was degassed for $30 \mathrm{~min}$. Next, the reaction was carried out at $50^{\circ} \mathrm{C}$ for $6 \mathrm{~h}$. The resulting sample was washed twice with a certain volume of ethanol/water $(30: 70)(\mathrm{v} / \mathrm{v}, \%)$ at $80^{\circ} \mathrm{C}$ for $30 \mathrm{~min}$ to obtain the polyacrylamide (PAM)-grafted jute fabric. The control sample and sample treated with either HRP or $\mathrm{H}_{2} \mathrm{O}_{2}$ followed the same condition as the HRP treatment $[7,20]$.

\subsection{Characterization of lignin}

\subsubsection{Gel permeation chromatography (GPC) analysis}

The relative molecular weight and polydispersity of the lignin, which was soluble in $\mathrm{N}, \mathrm{N}$-dimethyl formamide (DMF), were measured using a Waters 1515 gel permeation chromatograph and Waters 2414 refractive index detector. The measurements were performed at $35^{\circ} \mathrm{C}$, and DMF was used as the mobile phase at a flow rate of $1.5 \mathrm{~mL} / \mathrm{min}$, using polystyrene as the standard sample.

\subsubsection{Elemental analysis}

The carbon, hydrogen, and nitrogen contents in the lignin samples were determined using an elemental analyzer (Elementar Vario ZLIII, Germany). 
<smiles>CC(=O)CC(C)=O</smiles><smiles>C=CC(N)=O</smiles>

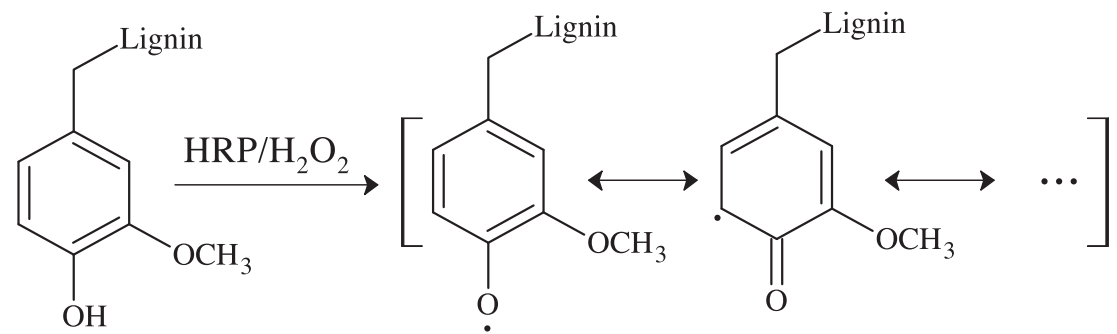

homopolymer<smiles>COC1=CC(C[123I])=CCC1=O</smiles>

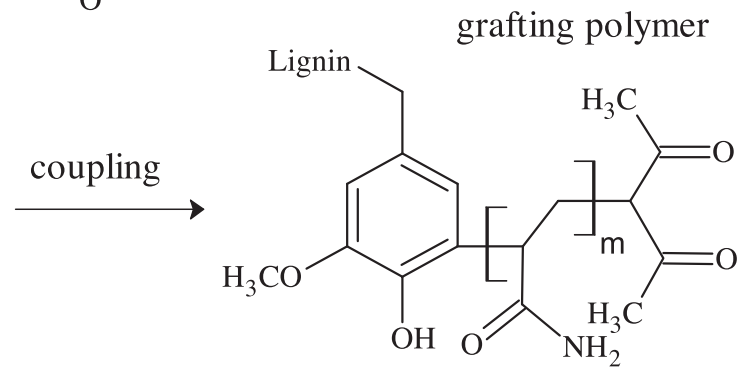

Fig. 2. Hypothetical mechanism of lignin and acrylamide polymerization catalyzed by HRP.

\subsubsection{Matrix-assisted laser desorption/ionization mass spectrometry (MALDI-TOF MS) analysis}

Formations of lignin treated with different chemicals were studied with a Bruker ultrafleXtreme MALDI-TOF/TOF MS (Bremen, Germany). For the MALDI-TOF MS analysis, the lignins were dissolved in N,N-dimethyl formamide (DMF). Sinapinic acid comparing to other matrices was found to give the best results for lignin analysis [27]. A volume of $2 \mu \mathrm{L}$ of the sample-matrix mixture was dried onto the MALDI target plate at room temperature. The positive ion mass spectra were acquired from the dried sample spots in reflector mode.

\subsubsection{Nuclear magnetic resonance (NMR) analysis}

The ${ }^{1} \mathrm{H}$ NMR spectra of $20 \mathrm{mg}$ acetylated lignins solved in $0.5 \mathrm{~mL}$ chloroform $\left(\mathrm{CDCl}_{3}\right)$ were recorded, using tetramethylsilane (TMS) as the internal standard in a Bruker Avance 400 spectrometer with an operating frequency at $400 \mathrm{MHz}$.

\subsection{Characterization of jute fabric surface}

\subsubsection{Fourier transform infrared (FT-IR) analysis}

The FTIR spectra were recorded using a Nicolet iS10 FT-IR spectrometer (Thermo Fisher Scientific, USA) with the attenuated total reflection (ATR) technique. The scan range was from $4000 \mathrm{~cm}^{-1}$ to $650 \mathrm{~cm}^{-1}$ at $4 \mathrm{~cm}^{-1}$ resolution and 32 scans per sample.

\subsubsection{Scanning electron microscopy (SEM) analysis}

The SEM micrographs were recorded using a SU1510 SEM (Hitachi, Japan) under $5.00 \mathrm{kV}$ at $3.00 \mathrm{~K}$ magnification. The surface of the jute fiber was coated with gold by vacuum evaporation.

\subsection{Hydrophilicity measurement}

The hydrophilicity of the jute samples was evaluated by wetting time, water contact angle, and equilibrium moisture regain. The wetting time was measured according to the AATCC Test Method 79-2007. The jute fabric swatch was planished under a standard atmospheric pressure for $24 \mathrm{~h}$ and then mounted on a plate, which was placed $\sim 10 \pm 1 \mathrm{~mm}$ below the tip of a buret, with a filter paper spread tightly to make sure that the surface was free of wrinkles and without distorting the structure of the material. A drop of distilled water was allowed to fall from a height of $2 \mathrm{~cm}$ onto the taut surface of the test specimen, and the time taken for the specular reflectance of the water drop to completely disappear was recorded using a stopwatch. Five readings were averaged as the wetting time.

The water contact angle was measured using a SL200B static contact angle/interfacial tension meter (Kino Industry) after $5 \mathrm{~s}$ of drop deposition and conditioning to equilibrium moisture content as mentioned above. Each sample was required to be measured at five spots, and then the results were averaged.

The equilibrium moisture regain was measured using the weighing method, in which the dry jute samples were placed under a standard atmospheric pressure for $24 \mathrm{~h}$ before weighing. The water absorption of the jute samples was calculated as follows:

Water absorption $(\%)=\frac{W_{2}-W_{1}}{W_{1}} \times 100$

where $W_{1}$ and $W_{2}$ are the weights of the dry and wet jute fibers, respectively. 
Table 1

The average molecular weight and polydispersity of lignin.

\begin{tabular}{lccc}
\hline Sample & Mn & Mw & Mw/Mn \\
\hline Lc & 25,769 & 44,429 & 1.724 \\
$\mathrm{Lt}_{1}$ & 27,898 & 52,263 & 1.873 \\
$\mathrm{Lt}_{2}$ & 27,483 & 48,705 & 1.772 \\
$\mathrm{Lt}_{3}$ & 25,422 & 43,803 & 1.723 \\
$\mathrm{Lt}_{4}$ & 25,724 & 43,833 & 1.704 \\
\hline
\end{tabular}

\subsection{Determination of nitrogen content and grafting percentage}

(GP)

According to the current standard of Determination of Protein Content in Food GB/T5009.5-2010 in China, the nitrogen content of jute-AM graft copolymer was measured with the micro-Kjeldahl method. The GP was calculated as follows:

$\mathrm{GP}(\%)=\frac{N_{P}-N_{C}}{N_{a}} \times 100$

where $N_{p}, N_{c}$, and $N_{a}$ are the nitrogen contents on the grafting jute, control jute, and initial AM monomer, respectively.

\subsection{Effect of process parameters on the grafting percentage}

The HRP-mediated polyacrylamide graft modification of raw jute fabric was carried out as a function of different enzymatic reaction variables such as dosages of AM $(0.5,1.0,1.5,2.0$ and $2.5 \mathrm{~g})$, $\operatorname{HRP}(0.5,1.0,1.5,2.0$ and $2.5 \mathrm{mg})$ and $\mathrm{H}_{2} \mathrm{O}_{2}(0.25,0.5,1.0,1.5$ and $2.0 \mathrm{~mL}), \mathrm{pH}$ of phosphate buffer $(5,6,7,8,9)$, incubation temperature $\left(20,30,40,50\right.$ and $\left.60^{\circ} \mathrm{C}\right)$, and incubation period $(3,4,5,6$ and $7 \mathrm{~h}$ ). The grafting was characterized by the grafting percentage (GP) measured by the nitrogen content of jute-AM graft copolymer as mentioned above.

\section{Results and discussion}

\subsection{Characterization of lignin}

\subsubsection{GPC analysis}

The molecular weight distribution curves of various treated lignins are shown in Fig. 3. The values of the number-average $\left(M_{n}\right)$ and weight-average $\left(M_{w}\right)$ molecular weights of the lignins were calculated from the curves (Table 1 ).

As shown in Table 1, the results of the control groups, the $M_{n}$ and $M_{w}$ of $\mathrm{Lc}, \mathrm{Lt}_{3}$, and $\mathrm{Lt}_{4}$ and the polydispersity value $\left(M_{w} / M_{n}\right)$ were smaller than the grafting group. The $M_{n}$ and $M_{w}$ values of $\mathrm{Lt}_{1}$ were 27898 and 52263, respectively, and the polydispersity value was 1.873. Compared to the results of other treated lignins, the $M_{w}$, $M_{n}$, and polydispersity values of $\mathrm{Lt}_{1}$ increased. Similar result was also obtained by Zhou et al. [22].

Compared to $\mathrm{Lt}_{3}$, the $M_{n}$ and $M_{w}$ values of $\mathrm{Lt}_{2}$ increased by $8.11 \%$ and $11.19 \%$, respectively. This indicates that HRP played an important role in the polymerization of the lignins of jute fabrics. Moreover, unlike $\mathrm{Lt}_{3}$, the $M_{n}$ and $M_{w}$ values of $\mathrm{Lt}_{1}$ increased by $9.74 \%$ and $19.31 \%$, respectively. Thus, the lignins in the jute fibers could be polymerized by the $\mathrm{HRP} / \mathrm{H}_{2} \mathrm{O}_{2}$ system. Compared to $\mathrm{Lt}_{3}$, the polydispersity value of $\mathrm{Lt}_{1}$ increased from 1.723 to 1.873 , while it increased by 0.049 for $\mathrm{Lt}_{2}$, indicating that the $\mathrm{HRP} / \mathrm{H}_{2} \mathrm{O}_{2}$-treated lignin had a wider distribution range of relative molecular mass than the ungrafted lignin.

\subsubsection{Elemental analysis}

The elemental analysis results of the lignins treated with different reagents showed an increase in the nitrogen content, indicating that AM was successfully grafted onto lignins (Table 2). The increase
Table 2

The element content of lignin.

\begin{tabular}{llll}
\hline Sample & $N(\%)$ & $C(\%)$ & $H(\%)$ \\
\hline $\mathrm{Lc}$ & 0.363 & 57.09 & 5.673 \\
$\mathrm{Lt}_{1}$ & 0.463 & 58.34 & 5.654 \\
$\mathrm{Lt}_{2}$ & 0.418 & 58.64 & 5.577 \\
$\mathrm{Lt}_{3}$ & 0.399 & 53.82 & 5.540 \\
$\mathrm{Lt}_{4}$ & 0.408 & 58.72 & 5.436 \\
\hline
\end{tabular}

Table 3

The $m / z$ of MALDI-TOF mass spectrum of lignins and the substance construction.

\begin{tabular}{ccl}
\hline$m / z(\mathrm{Da})$ & & Element \\
\hline Grated sample & Control sample & \\
\hline 351.197 & 351.151 & $2 \mathrm{M}$ \\
434.558 & 434.491 & $2 \mathrm{M}$ \\
469.172 & 469.120 & $2 \mathrm{M}$ \\
471.192 & 471.137 & $2 \mathrm{M}$ \\
534.065 & - & $2 \mathrm{M}+2 \mathrm{AM}$ \\
649.295 & 649.225 & $3 \mathrm{M}$ \\
677.293 & 677.222 & $3 \mathrm{M}$ \\
695.307 & 695.233 & $3 \mathrm{M}$ \\
711.293 & 711.210 & $3 \mathrm{M}$ \\
749.254 & - & $3 \mathrm{M}+1 \mathrm{AM}$ \\
887.383 & 887.286 & $4 \mathrm{M}$ \\
917.389 & 917.295 & $4 \mathrm{M}$ \\
933.377 & 933.267 & $4 \mathrm{M}$ \\
935.390 & 935.287 & $4 \mathrm{M}$ \\
957.382 & 957.276 & $4 \mathrm{M}$ \\
979.382 & - & $3 \mathrm{M}+4 \mathrm{AM}$ \\
995.365 & - & $3 \mathrm{M}+4 \mathrm{AM}$ \\
1141.496 & 1141.370 & $5 \mathrm{M}$ \\
1197.460 & - & $5 \mathrm{M}$ \\
1365.611 & 1365.447 & $6 \mathrm{M}$ \\
1421.568 & - & $6 \mathrm{M}$ \\
\hline
\end{tabular}

in the nitrogen content from $0.418\left(\mathrm{Lt}_{2}\right)$ to $0.463\left(\mathrm{Lt}_{1}\right)$ can be attributed to the high nitrogen content of $\mathrm{AM}\left(\mathrm{C}_{3} \mathrm{H}_{5} \mathrm{NO}\right)$.

Moreover, compared to other samples, the rates of change in the nitrogen content of the lignins were $27.55 \%$ (from $\mathrm{Lt}_{1}$ to $\mathrm{Lc}$ ), $10.76 \%$ (from $\mathrm{Lt}_{1}$ to $\mathrm{Lt}_{2}$ ), $16.04 \%$ (from $\mathrm{Lt}_{1}$ to $\mathrm{Lt}_{3}$ ), and $13.48 \%$ (from $\mathrm{Lt}_{1}$ to $\mathrm{Lt}_{4}$ ). Moreover, an increase in the nitrogen content of the $\mathrm{HRP} / \mathrm{H}_{2} \mathrm{O}_{2}$-treated sample may result from the absorbed enzyme proteins on lignins. However, the increase in the nitrogen content of the $\mathrm{HRP} / \mathrm{H}_{2} \mathrm{O}_{2} / \mathrm{AM}$-treated sample may be suppressed due to the incorporation of AM to lignins, which achieved the same effect in the study on grafting AM to jute fibers by laccase [7].

\subsubsection{MALDI-TOF MS analysis}

The MALDI-TOF mass spectra of the control and grafted lignins were shown in Fig. 4. A molecular weight distribution from two hundred to more than one thousand Da is evident. The spectra have pronounced fine structure which may be assigned to the different groups of oligomers, from ca. $400 \mathrm{Da}$ for the dimers to $1400 \mathrm{Da}$ for the heptamers. These mass spectra show a similar structure to those obtained by Bocchini et al. [27]. According to the study of Bocchini et al., sequences of signals, with $\Delta m=14-18$ mass units for the dimers $(m / z 351,393,434,455$ and 469 related to nonmethylated GG and SS units), the trimers ( $m / z$ 649, 677 and 695) and the tetramers ( $m / z 887,917$ and 933$)$ were confirmed in natural and synthetic lignins. In Fig. 4 and Table 3, the MALDI-TOF mass spectrum ions of grafted lignin show some differences compared to the control sample at molar mass $534 \mathrm{Da}, 749 \mathrm{Da}, 979 \mathrm{Da}$, and $995 \mathrm{Da}$, which were the peaks of the polymer of lignins and polyacrylamide or acrylamide. In addition, another two points at 1197 Da and 1421 Da showing the molecular weight of grated lignin was more than that of control lignin, which revealed that HRP can 


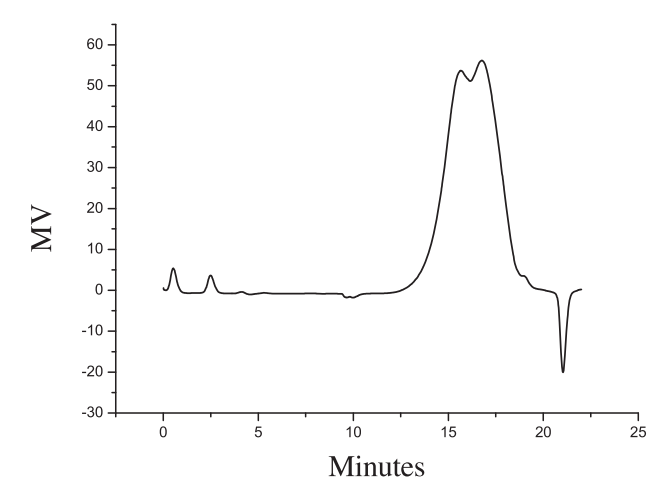

(a)

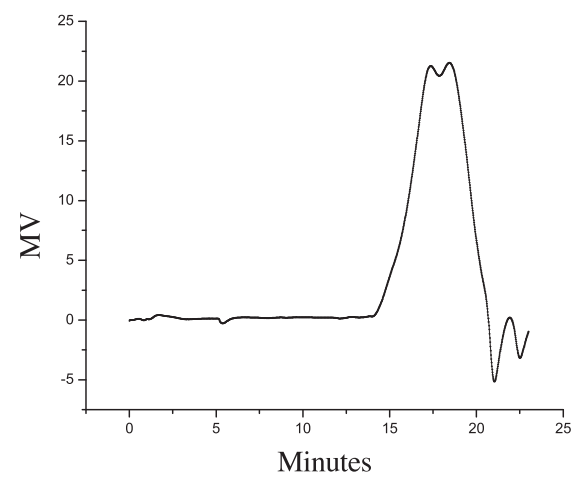

(b)

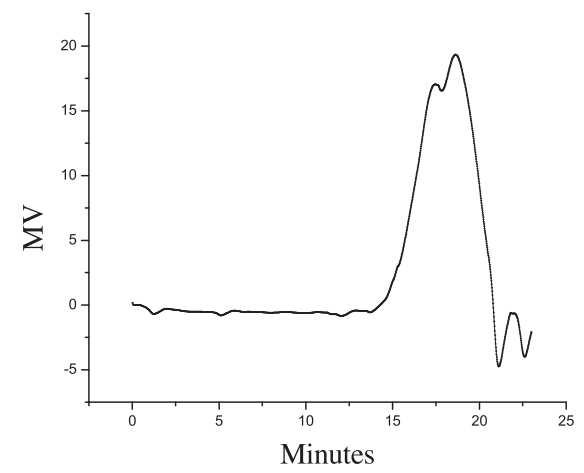

(d)

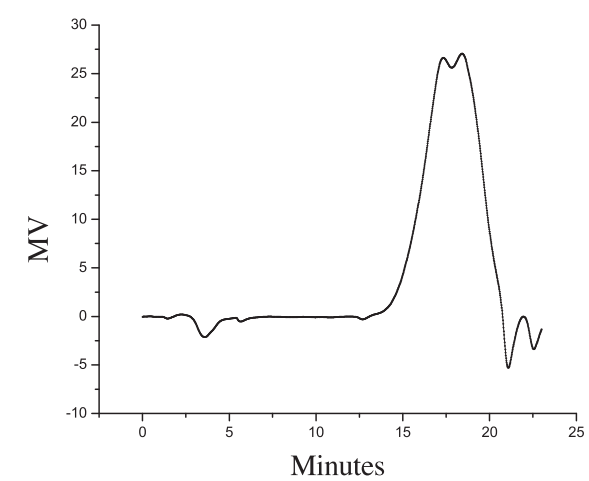

(c)

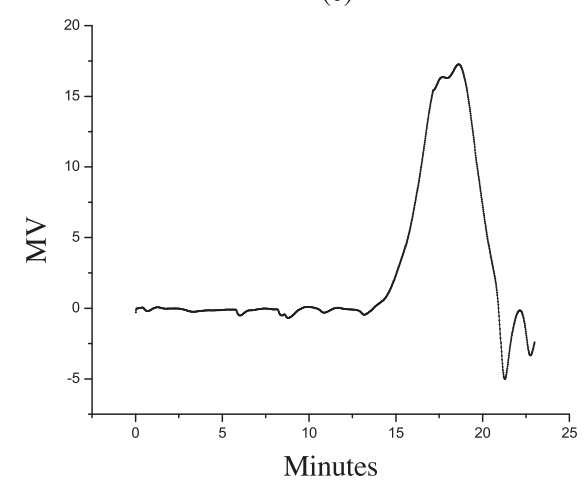

(e)

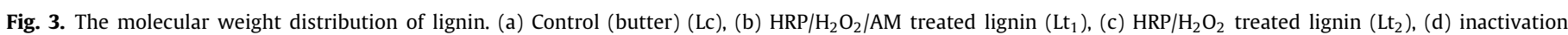
$\mathrm{HRP} / \mathrm{H}_{2} \mathrm{O}_{2} / \mathrm{AM}$ treated lignin ( $\left.\mathrm{Lt}_{3}\right),(\mathrm{e}) \mathrm{H}_{2} \mathrm{O}_{2} / \mathrm{AM}$ treated lignin $\left(\mathrm{Lt}_{4}\right)$.

make the polymerization of lignins as the same result in above GPC analysis.

\subsection{4. ${ }^{1} \mathrm{H}$ NMR analysis}

The ${ }^{1} \mathrm{H}$ NMR spectra obtained for the grafted and control lignins were shown in Fig. 5, and Table 4 listed the position of signals assigned by Sarwar Jahan et al. [28,29]. The position of lignin in the present samples was almost the same. The main assignments such as aromatic protons (two peaks in the aromatic proton region, which correspond to guaiacyl units $(\delta 6.971)$ and syringyl units $(\delta 6.616)$ ), $\beta-0-4$ structure $(\delta$ 6.014), $\beta-5$ structure (where there is no noticeable signal in range number 4 between ppm $\delta$ 5.20 and $\delta 5.75$ indicating low amount of phenylcoumaran units in the lignin structure.), $\beta-1$ and $\beta-\beta$ structures were similar in Fig. $5 a$ and $b$. While, a noticeable and different signal was shown in Fig. 5b, i.e., ppm $\delta 1.20\left(\mathrm{H}_{\beta}\right.$ in the chain $\mathrm{CH}_{2}$ of the ends of $\left.\operatorname{PAM}\left(-\mathrm{CH}_{2}-\mathrm{CH}_{2}-\mathrm{CH}_{2}-\mathrm{CONH}_{2}\right)\right)$. In addition, the signal $\mathrm{H}$ of amide group structure ( $\delta 6.0$ ) may be covered by that of $\mathrm{H}_{\alpha}$ of $\beta-0-4$ and $\beta$-1 structures. $\mathrm{H}_{\alpha}$ of main chain $\mathrm{CH}$ of PAM $\left(-\mathrm{CHCONH}_{2} \mathrm{CH}_{2}-\right)$ and
$\mathrm{H}_{\beta}$ of $\beta-\beta$ structures (between $\delta 2.50$ and $\delta 3.10$ ) might have a same ppm [30].

\subsection{FT-IR analysis of jute fabrics}

FT-IR spectroscopy is a powerful technique to reveal the changes in the hydroxyl, carbonyl, and other functional groups in a polymer. The FTIR-ATR spectra of the untreated jute fiber (A) and jute fiber grafted with AM (B) are shown in Fig. 6; some differences between the two fibers were observed. The $\mathrm{O}-\mathrm{H}$ stretching vibration peak in the FTIR-ATR spectra appeared at $3337 \mathrm{~cm}^{-1}$; the $\mathrm{C}-\mathrm{H}$ vibrations of methyl and methylene groups appeared at $2884 \mathrm{~cm}^{-1}$. The peaks at 1233,1099 , and $1035 \mathrm{~cm}^{-1}$ represent the $\mathrm{C}-\mathrm{O}$ vibrations of cellulose, and the absorbance bands at $1451 \mathrm{~cm}^{-1}$ show the aromatic skeletal vibration of lignin [31]. Compared to the control jute sample, the spectrum of the grafted jute fabric showed three strong peaks at $1660 \mathrm{~cm}^{-1}\left(\mathrm{C}=\mathrm{O}\right.$ group), $1590 \mathrm{~cm}^{-1}(\mathrm{~N}-\mathrm{H}$ group), and $1312 \mathrm{~cm}^{-1}$ (C-N group) [32]. The differences in the two spectra indicate that AM was grafted onto the jute fabrics in 


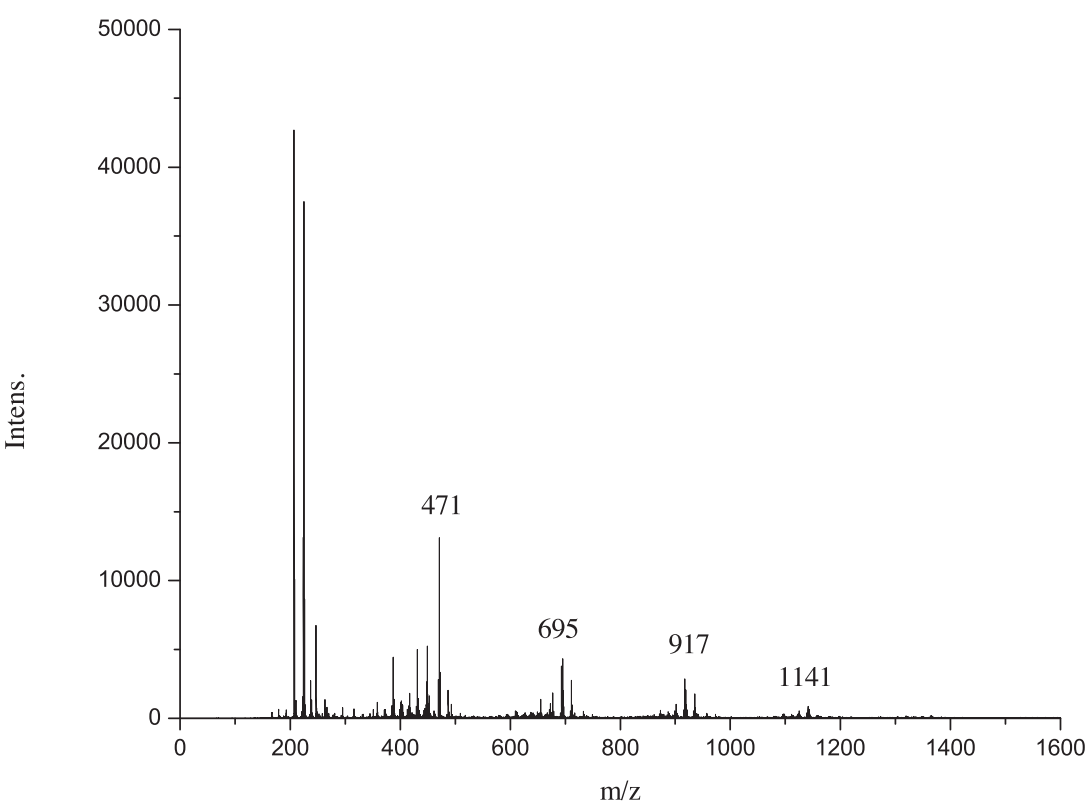

(a)

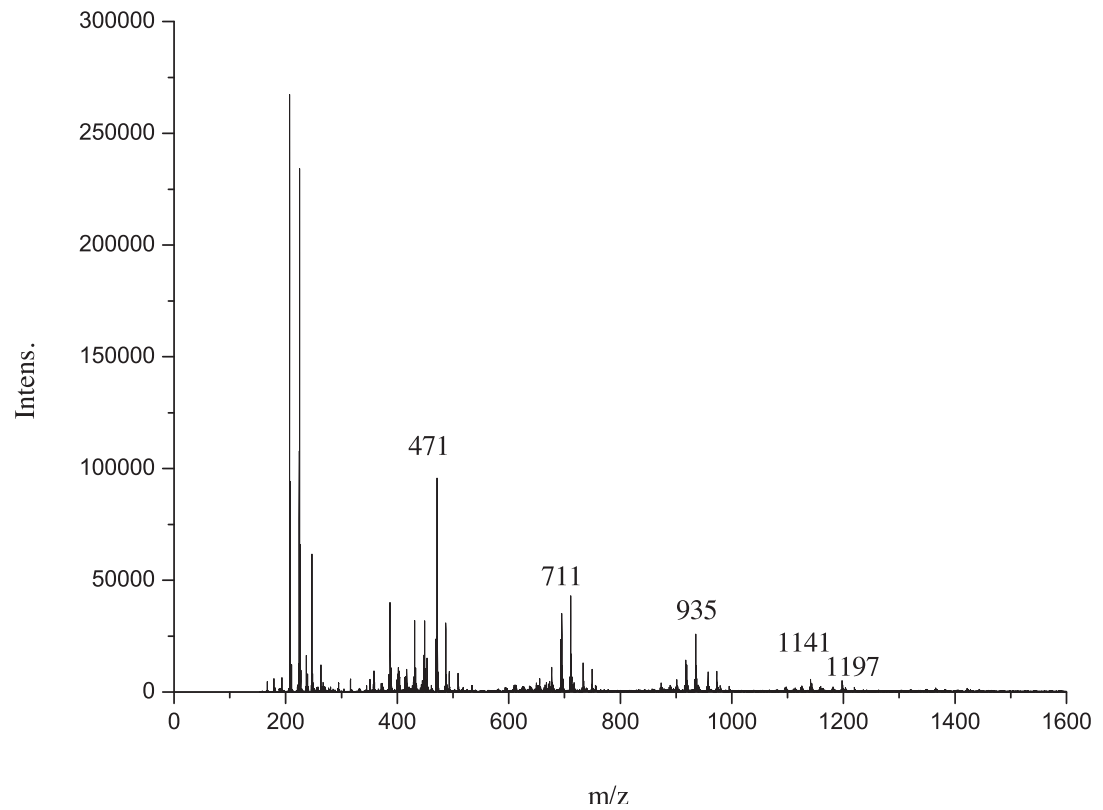

(b)

Fig. 4. Expanded section of MALDI-TOF mass spectra of the control (a) and grafted (b) lignins.

Table 4

Assignment of signals in the ${ }^{1} \mathrm{H}$ NMR spectra of the control and grafted lignins.

\begin{tabular}{|c|c|c|c|}
\hline Range number & Range (ppm) & ppm of the maximum & Main assignments \\
\hline & 7.30 & 7.272 & Chloroform (solvent) \\
\hline 1 & $7.25-6.80$ & 6.971 & Aromatic proton in guaiacyl units \\
\hline 2 & $6.80-6.25$ & 6.616 & Aromatic proton in guaiacyl units \\
\hline 3 & $6.25-5.75$ & 6.014 & $\mathrm{H}_{\alpha}$ of $\beta-0-4$ and $\beta-1$ structures, $\mathrm{H}$ of amide group structure \\
\hline 4 & $5.75-5.20$ & 5.434 & $\mathrm{H}_{\alpha}$ of $\beta-5$ structure \\
\hline 5 & $5.20-4.90$ & 5.092 & $\mathrm{H}$ of xylan residue \\
\hline 6 & $4.90-4.30$ & 4.439 & $\mathrm{H}_{\alpha}$ and $\mathrm{H}_{\beta}$ of $\beta-\mathrm{O}-4$ structures \\
\hline 7 & $4.30-4.00$ & 4.173 & $H_{\alpha}$ of $\beta-\beta$ structures, $\mathrm{H}$ of xylan residue \\
\hline 8 & $4.00-3.48$ & 3.757 & $\mathrm{H}$ of methoxyl groups \\
\hline 9 & $3.10-2.50$ & 2.619 & $\mathrm{H}_{\beta}$ of $\beta-\beta$ structures, $\mathrm{H}_{\alpha}$ of main chain $\mathrm{CH}$ of PAM \\
\hline 10 & $2.50-2.22$ & 2.292 & $\mathrm{H}$ of aromatic acetates \\
\hline 11 & $2.22-1.60$ & 2.011 & $\mathrm{H}$ of aliphatic acetates \\
\hline 12 & $1.60-1.30$ & 1.391 & Hydrocarbon protons \\
\hline 13 & 1.20 & 1.208 & $\mathrm{H}_{\beta}$ of main chain $\mathrm{CH}_{2}$ of PAM \\
\hline
\end{tabular}




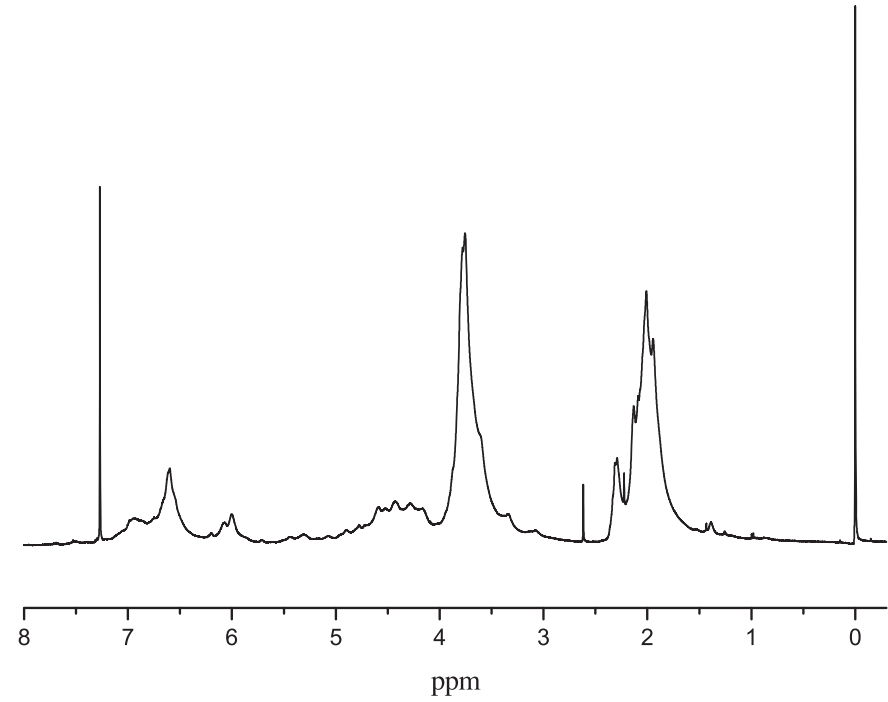

(a)
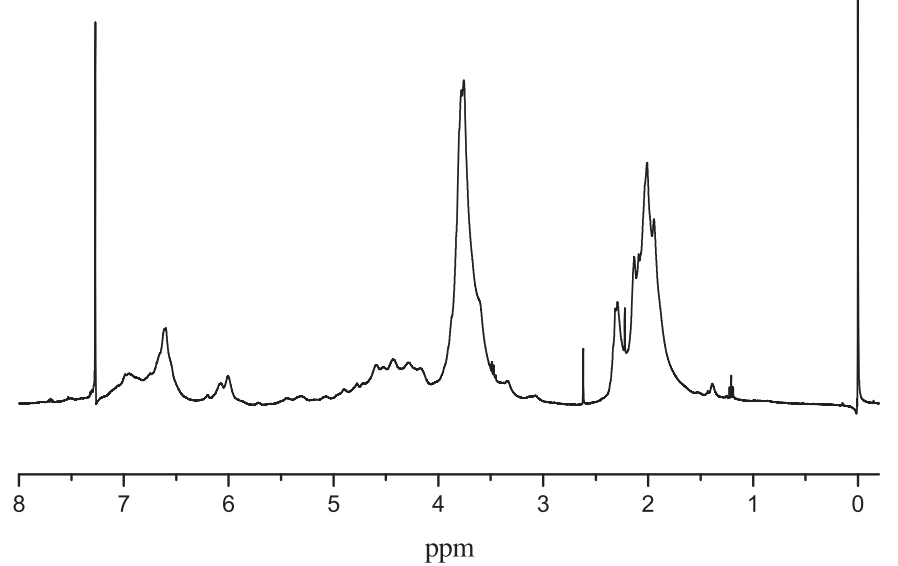

(b)

Fig. 5. ${ }^{1} \mathrm{H}$ NMR spectra of the control (a) and grafted (b) lignins.

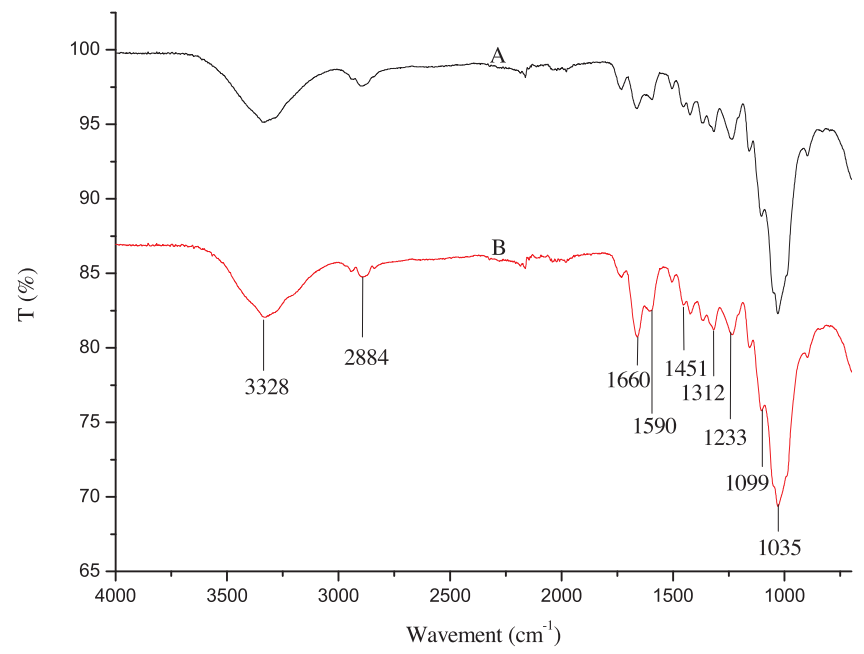

Fig. 6. FTIR-ATR spectra of the untreated jute fiber $(A)$ and the AM-grafted jute fiber (B). the presence of $\mathrm{HRP}$ and $\mathrm{H}_{2} \mathrm{O}_{2}$. Therefore, the surface properties such as the hydrophilicity of jute fiber could be improved.

Other than lignin, cellulose is also present in jute fabrics. Therefore, to verify that lignin was the only substrate for the HRP catalysis, the cellulose was investigated. A bleached cotton fabric with AM-grafted cellulose was investigated, which would demonstrate whether or not AM was grafted onto cellulose structure by HRP. The peaks at $1660 \mathrm{~cm}^{-1}$ in the FTIR-ATR spectra of the bleached cotton fibers, treated with HRP, inactivated HRP, or phosphate buffer ( $0.1 \mathrm{M}, \mathrm{pH} 7.0)$ instead of HRP were very similar (data not shown), suggesting that no AM was grafted onto the cellulose of the fibers by HRP catalysis.

The probable mechanism of the $\mathrm{HRP} / \mathrm{H}_{2} \mathrm{O}_{2}$ system has been studied $[10,33,34]$. In this paper, a probable mechanism of HRPcatalyzed grafting modification of lignin on the surface of jute fibers in the presence of $\mathrm{H}_{2} \mathrm{O}_{2}$ is proposed based on our investigation, as shown in Fig. 2. The carbonyl group of ACAC first undergoes an oxidation reaction catalyzed by HRP in the presence of $\mathrm{HRP} / \mathrm{H}_{2} \mathrm{O}_{2}$, forming the corresponding radicals. Then, the radicals transfer electrons to the phenolic hydroxyl group of lignin and AM, forming the reactive radicals for grafting AM onto the lignin of jute fabrics and modifying the jute fabric surface. The side reaction is the homopolymerization of AM. The reaction is terminated by the copolymerization between lignin and AM radicals, polymerization of AM, and crosslinking or degradation of lignins.

\subsection{SEM analysis of jute fabrics}

The morphology of various treated jute fibers was observed by SEM. As shown in Fig. 7, the four types of jute fibers exhibited different structures. The surfaces of the ungrafted jute fibers were smooth, tidy, and neatly arranged with few impurities on the surface (Fig. 7a, b, and d). The $2 \mathrm{~h}$ water reflux removed the starch and PVA sizes, but was unable to dislodge the pectins on jute fabrics. Compared to the untreated jute fibers, the surface of the grafted jute fibers was rough and irregular (Fig. 7c), probably because of the graft copolymers of PAM. Moreover, the grafted jute fibers exhibited damaged-like porous structures. For instance, the surface of the $\mathrm{H}_{2} \mathrm{O}_{2}$-untreated fibers had a smooth, complete, and compact structure (Fig. 7a and b). In contrast, the surface of the $\mathrm{H}_{2} \mathrm{O}_{2}$-treated fibers had a rough, damaged-like, and slightly loose structure with small pores (Fig. 7c and d). The damaged-like porous structure of the grafted jute fibers was probably influenced by the $\mathrm{H}_{2} \mathrm{O}_{2}$ concentration.

\subsection{Determination of nitrogen content and grafting percentage}

The results of the nitrogen content of jute fibers are shown in Table 5. The nitrogen contents of the AM-grafted and control (only HRP-treated) jute fibers were $0.3902 \%$ and $0.1730 \%$, respectively. Compared to the grafting rate of the control $(0.1949 \%)$, the grafted jute fibers catalyzed by the $\mathrm{HRP} / \mathrm{H}_{2} \mathrm{O}_{2}$ system with a grafting rate of $2.29 \%$ achieved the same effect as the result shown in Table 2 and provided another evidence for the grafting of AM onto the jute surface. Moreover, the nitrogen contents of the jute fibers treated with HRP alone, $\mathrm{H}_{2} \mathrm{O}_{2}$ alone, and neither in the presence of AM were almost identical. It was shown that, without $\mathrm{HRP}$ or $\mathrm{H}_{2} \mathrm{O}_{2}$, the graft copolymerization of AM onto the lignins in the jute fibers did not occur with the desired properties such as hydrophilicity and feeble tickle. The results are different from those obtained from the studies by Mai et al. [35-37] and Dong et al. [7], which showed that the catalysis by laccase alone was able but insufficient to produce copolymerizates. 

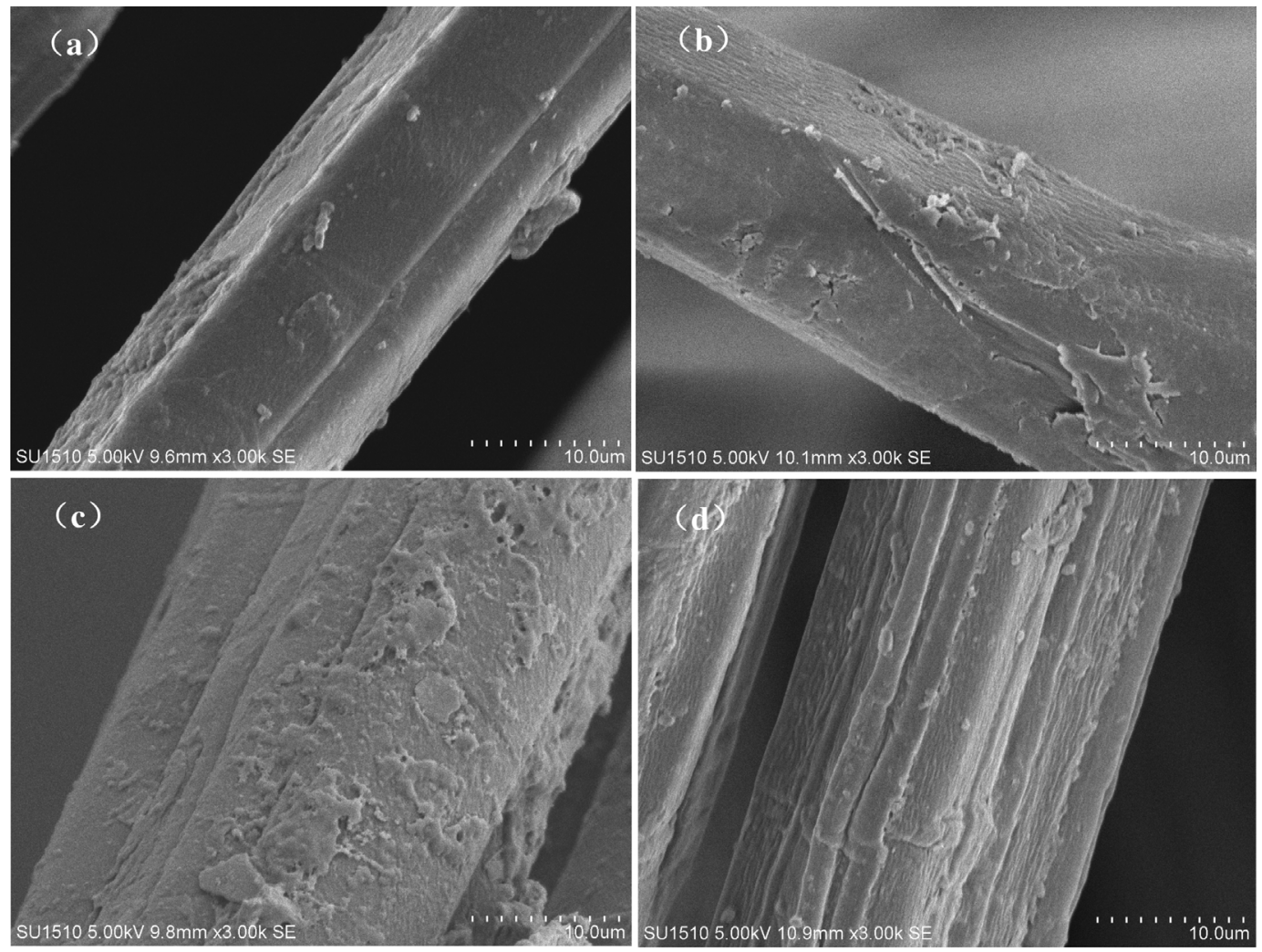

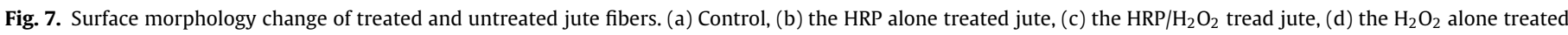
jute.

Table 5

The nitrogen content of the jute fiber.

\begin{tabular}{|c|c|c|c|c|}
\hline Treatment & $\mathrm{HRP} / \mathrm{H}_{2} \mathrm{O}_{2}$ & HRP alone & $\mathrm{H}_{2} \mathrm{O}_{2}$ alone & Control \\
\hline$N(\%)$ & 0.6529 & 0.1730 & 0.1840 & 0.1949 \\
\hline$V_{\mathrm{HCl}}(\mathrm{mL})$ & 1.8842 & 0.6464 & 0.5975 & 0.5689 \\
\hline $\mathrm{GP}(\%)$ & 2.29 & - & - & - \\
\hline
\end{tabular}

\subsection{Effect of process parameters on the grafting percentage}

The effect of enzymatic reaction conditions including AM dosage, $\mathrm{HRP}$ dosage, $\mathrm{H}_{2} \mathrm{O}_{2}$ dosage, $\mathrm{pH}$ of phosphate buffer, incubation temperature, and incubation period on the grafting percentage were shown in Fig. 8. Fig. 8a and b indicated that the grafting percentage increased greatly with the addition of AM or HRP until reached its maximum value and then decreased. This revealed that the increase in monomer or HRP concentration might accelerate the homopolymerization reaction rather than grafting after a certain limit, thus decreasing the grafting yield. According to the curve of $\mathrm{H}_{2} \mathrm{O}_{2}$ dosage (Fig. $8 \mathrm{c}$ ), the grafting percentage decreased with increasing $\mathrm{H}_{2} \mathrm{O}_{2}$ dosage due to the degradation of $\mathrm{HRP}$ by $\mathrm{H}_{2} \mathrm{O}_{2}$, which canceled out the catalytic activity of the enzyme [38]. The effect of $\mathrm{pH}$ and temperature on the enzymatic grafting (Fig. 8d and e) corresponded roughly with that on the HRP activity (data not shown). The grafting percentage remarkably increased with increasing of incubation period and then decreased slowly (Fig. 8f). This phenomenon may be explained by the slow decay of the enzyme activity [39].

\subsection{Effect of AM grafting on hydrophilicity of jute fabric}

The surface hydrophilicity of the jute fabric was investigated in terms of water contact angle, wetting time, and balance moisture regain. As shown in Table 6, the HRP treatment alone (121.68 ${ }^{\circ}$ ) and
Table 6

The hydrophilicity of the jute fiber.

\begin{tabular}{lrrr}
\hline Treatment & Wetting time $(\mathrm{min})$ & Contact angle $\left(^{\circ}\right)$ & \multicolumn{1}{c}{$\begin{array}{l}\text { Balance moisture } \\
\text { regain }(\%)\end{array}$} \\
\hline Control & $11.62 \pm 0.59$ & $122.30 \pm 1.86$ & $9.78 \pm 0.36$ \\
$\mathrm{HRP} / \mathrm{H}_{2} \mathrm{O}_{2}$ & $7.45 \pm 0.79$ & $92.84 \pm 2.23$ & $10.40 \pm 0.40$ \\
$\mathrm{HRP}$ alone & $11.38 \pm 0.69$ & $121.68 \pm 3.45$ & $10.06 \pm 0.38$ \\
$\mathrm{H}_{2} \mathrm{O}_{2}$ alone & $13.24 \pm 0.83$ & $118.65 \pm 4.47$ & $9.87 \pm 0.29$ \\
\hline
\end{tabular}

$\mathrm{H}_{2} \mathrm{O}_{2}$ treatment alone (118.65 ${ }^{\circ}$ ) merely caused a slight decrease in the water contact angle in contrast to the control treatment $\left(122.30^{\circ}\right)$. However, the jute fabric grafted with AM catalyzed by the $\mathrm{HRP} / \mathrm{H}_{2} \mathrm{O}_{2}$ system showed a water contact angle of $92.84^{\circ}$, representing a decrease of $29.46^{\circ}$ compared to the control jute fabrics.

The wetting time of the grafted jute fabrics catalyzed by the $\mathrm{HRP} / \mathrm{H}_{2} \mathrm{O}_{2}$ system was also lower than the other three samples, consistent with the water contact angle. Moreover, the balance moisture regain of the grafted jute was higher than the other samples.

In conclusion, the wetting time, contact angle, and balance moisture regain of the grafted jute fiber were $7.45 \mathrm{~min}, 92.84^{\circ}$, and $10.40 \%$, respectively, which were clearly much better than the others and indicated that the hydrophilicity of the jute fibers was enhanced after grafting PAM and introducing the amide hydrophilic group $\left(\mathrm{CONH}_{2}\right)$. 


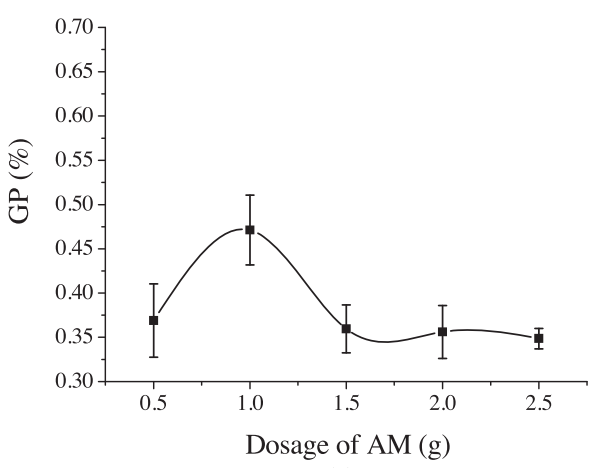

(a)

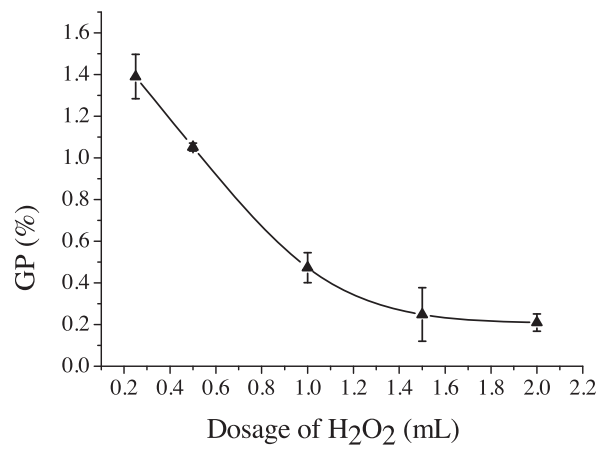

(c)

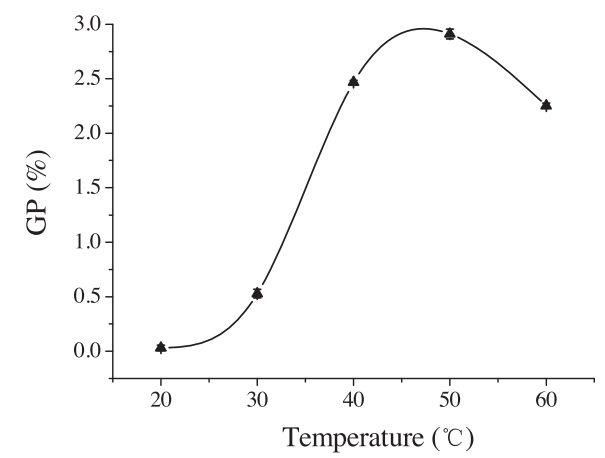

(e)

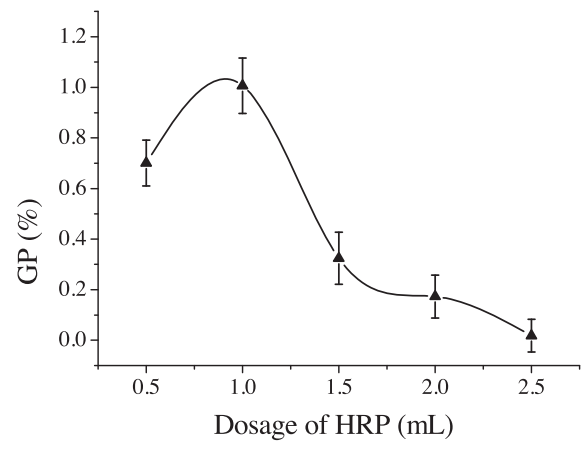

(b)

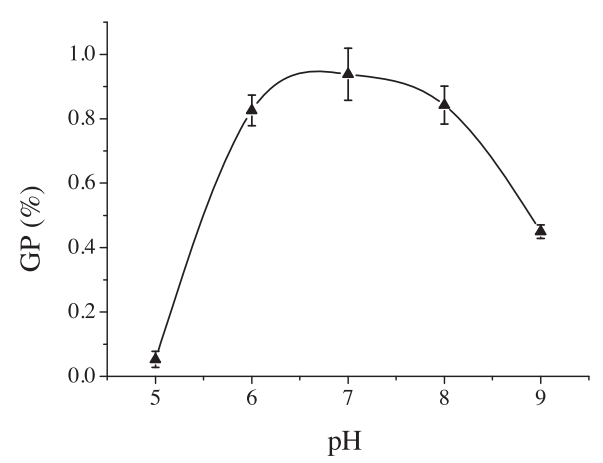

(d)

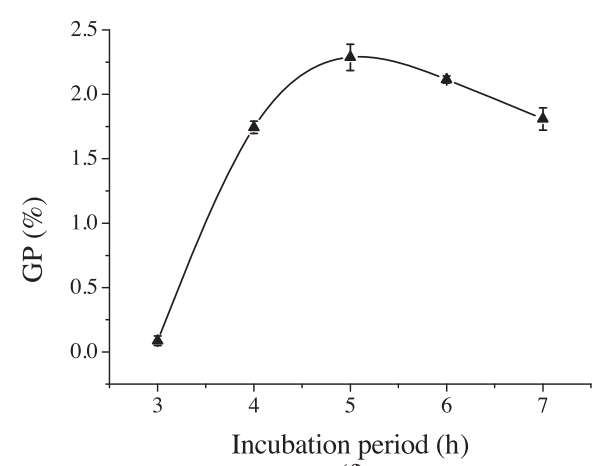

(f)

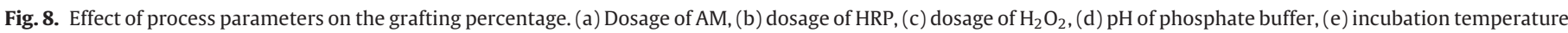
and (f) incubation period.

\section{Conclusions}

In this study, the grafting modification of jute fabrics was performed with AM monomer using HRP as the catalyst. The initial system of $\mathrm{HRP} / \mathrm{H}_{2} \mathrm{O}_{2} /$ ACAC could start the graft copolymerization of AM onto the lignin in jute fibers which was proved by GPC, elemental analysis, MALDI-TOF MS and ${ }^{1} \mathrm{H}$ NMR. The HRP in the reaction medium was essential for the initiation of the free-radical polymerization process, but the catalysis alone was ineffective to produce the grafting copolymers. The characteristic absorption peaks of the $\mathrm{C}=\mathrm{O}$ vibration, $\mathrm{N}-\mathrm{H}$ vibration, and $\mathrm{C}-\mathrm{N}$ vibration of the $-\mathrm{CONH}_{2}$ group shown in the FTIR-ATR spectra and the rough surface of the grafted jute fibers in the SEM image also confirm that AM was grafted onto the jute fibers, introducing the $-\mathrm{CONH}_{2}$ group, and that the grafting mechanism was free-radical grafting mechanism. The introduced $-\mathrm{CONH}_{2}$ group improved the desired property, hydrophilicity, as characterized by the wetting time, water contact angle, and balance moisture regain. Moreover, the grafting reaction had a low grafting rate, unfortunately because of the heterogeneous catalysis compared to the chemical grafting or coating by couplers. In the future, the enhancement of AM grafting by adding transition monomers in the reaction will be investigated.

\section{Acknowledgments}

This work was financially supported by the National Natural Science Foundation of China (51173071), the Program for New Century Excellent Talents in University (NCET-12-0883), the Program for Changjiang Scholars and Innovative Research Team in University (IRT1135), the Fundamental Research Funds for the Central Universities (JUSRP51312B) and the Graduate Student Innovation Plan of Jiangsu Province of China (SJLX_0527).

\section{References}

[1] K.E. Achyuthan, A.M. Achyuthan, P.D. Adams, S.M. Dirk, J.C. Harper, B.A. Simmons, A.K. Singh, Molecules 15 (2010) 8641-8688. 
[2] R.M. Isroi, S. Syamsiah, C. Niklasson, M.N. Cahyanto, K. Lundquist, M.J. Taherzadeh, BioResources 6 (2011) 5224-5259.

[3] J.C. del Río, J. Rencoret, G. Marques, J. Li, G. Gellerstedt, J. Jiménez-Barbero, A.T. Martínez, A. Gutiérrez, J. Agric. Food Chem. 57 (2009) 10271-10281.

[4] R.L. Chen, B.V. Kokta, C. Daneault, J.L. Valade, J. Appl. Polym. Sci. 32 (1986) $4815-4826$.

[5] S. Marais, F. Gouanve, A. Bonnesoeur, J. Greneta, F. Poncin-Epaillardb, C. Morvanc, M. Métayer, Compos. Part A 36 (2005) 975-986.

[6] C. Albanoa, J. Reyes, M. Ichazo, J. Gonzálezc, M. Britob, D. Moronta, Polym. Degrad. Stab. 76 (2002) 191-203.

[7] A.X. Dong, J.G. Yuan, Q. Wang, X.R. Fan, J. Appl. Polym. Sci. 131 (2014) 40387-40392.

[8] E. Aracri, A. Fillat, J.F. Colom, A. Gutiérrez, J.C. Del Río, A.T. Martínez, T. Vidal, Bioresour. Technol. 101 (2010) 8211-8216.

[9] (a) M. Kohri, H. Fukushima, T. Taniguchi, T. Nakahira, Polym. J. 42 (2010) 952-955;

(b) H. Uyama, in: K. Loos (Ed.), Biocatalysis on Polymer Chemistry, 1st ed., Wiley-VCH Verlag \& Co. KGaA, Weinheim, 2011, p. 165.

[10] F. Hollmann, I.W.C.E. Arends, Polymers 4 (2012) 759-766.

[11] S. Sgalla, G. Fabrizi, S. Cacchi, A. Macone, A. Bonamore, A. Boffi, J. Mol. Catal. B: Enzym. 44 (2007) 144-148.

[12] H.L. Chul, J.Y. Young, Process Biochem. 36 (2000) 233-241.

[13] S.H. Lv, T. Sun, Q.F. Zhou, J.J. Liu, H.D. Ding, Carbohydr. Polym. 103 (2014) 285-293.

[14] F. Hollmann, in: K. Loos (Ed.), Biocatalysis on Polymer Chemistry, 1st ed., WileyVCH Verlag \& Co. KGaA, Weinheim, 2011, p. 143.

[15] (a) A. Durand, T. Lalot, M. Brigodiot, E. Maréchal, Polymer 41 (2000) 8183-8192; (b) B. Kalra, R.A. Gross, Green Chem. 4 (2002) 174-178.

[16] B. Kalra, R.A. Gross, Biomacromolecules 1 (2000) 501-505

[17] A. Singh, D. Ma, D.L. Kaplan, Biomacromolecules 1 (2000) 592-596.

[18] G. Qi, C.W. Jones, F.J. Schork, Biomacromolecules 7 (2006) 2927-2930.

[19] R.L. Shogren, J.L. Willett, A. Biswas, Carbohydr. Polym. 75 (2009) 189-191.

[20] G.N. Fan, J.C. Zhao, Y.K. Zhang, Z.A. Guo, Polym. Bull. 56 (2006) 507-515.
[21] H. Liu, F.K. Yang, L.H. Qiu, Sci. Eng. Polym. Mater. 17 (2001) 173-175.

[22] H.F. Zhou, D.J. Yang, X.Q. Qiu, X.L. Wu, Y. Li, Biotechnol. Products Process Eng. 97 (2013) 10309-10320.

[23] B. Stellmach, Bestimmungsmethoden Enzyme Für Pharmazie, Lebensmittelchemie, Technik, Biochemie, Biologie, Medizin, Steinkopff-Verlag, Darmstadt, 1988, pp. 217-223.

[24] D.V. Evtuguin, C.P. Neto, A.M. Silva, P.M. Domingues, F.M. Amado, D. Robert, O. Faix, J. Agric. Food Chem. 49 (2001) 4252-4261.

[25] Y.B. Zhang, Q. Wang, X.R. Fan, J.G. Yuan, J. Mol. Catal. B: Enzym. 101 (2014) $133-136$.

[26] K. Lundquist, B. Ohlsson, R. Simonson, Svensk paperstidning 80 (1977) $143-144$.

[27] P. Bocchini, G.C. Galletti, R. Seraglia, P. Traldi, S. Camarero, A.T. Martinez, Rapid Commun. Mass Spectrom. 10 (1996) 1144-1147.

[28] M. Sarwar Jahan, S.P. Mun, J. Sci. Ind. Res. 44 (2009) 271-280.

[29] T.T. Yan, Y.Q. Xu, C.W. Yu, J. Appl. Polym. Sci. 114 (2009) 1896-1901.

[30] S.H. Lv, Y.F. Ma, D. Li, Adv. Mater. Res. 455-456 (2012) 582-588.

[31] F. Chen, J.X. Chen, Trans. China Pulp Pap. 9 (1994) 80.

[32] H.L. Zheng, P. Zhang, G.C. Zhu, C.J. Zhu, J.J. Wang, S.J. Jiang, Spectrosc. Spectra Anal. 11 (2011) 2944-2947.

[33] O. Emery, T. Lalot, M. Brigodiot, E. Marechal, J. Polym. Sci.: Part A: Polym. Chem. 35 (1997) 3331-3333.

[34] G.S. Nyanhongo, E. Nugroho Prasetyo, E. Herrero Acero, G.M. Guebitz, Chem. Eng. Technol. 35 (2012) 1359-1372.

[35] C. Mai, A. Majcherczyk, A. Hüttermann, Enzyme Microb. Technol. 27 (2000) $167-175$.

[36] C. Mai, O. Milstein, A. Hüttermann, J. Biotechnol. 79 (2000) 173-183.

[37] C. Mai, O. Milstein, A. Hüttermann, Appl. Microbiol. Biotechnol. 51 (1999) 527-531.

[38] A. Durand, T. Lalot, M. Brigodiot, E. Maréchal, Polymer 41 (2000) 8183-8192.

[39] E. Battistel, M. Morra, M. Marinetti, Appl. Surf. Sci. 177 (2001) 32-41. 